\title{
Path dependency and the interdependences of demand and supply in macroeconomics
}

\author{
Malcolm Sawyer*
}

\begin{abstract}
The paper argues that macroeconomic analysis has to be based on path dependency which is treated as a broader concept than hysteresis. The ways in which path dependency necessarily arises in the context of the dual role of investment on demand and capacity formation are next considered. The effects of demand on the path of the economy are then considered in respect of the operations of the labour market and then technical change. The relationship between the short run and the slong run in the form of the cycle and trend growth are considered leading simple formulations of aspects of such path dependency to postulate the way to consider the growth process.

JEL classifications: $B_{52}, E_{I 2}, O_{40}$

Keywords: path dependency, hysteresis, classical dichotomy, macroeconomics
\end{abstract}

\section{Introduction}

The independence of demand and supply has been a (perhaps ,the??) central proposition in mainstream economics, whether at the microeconomic level where the demand and supply curves only interact through the price mechanism with a separation of the factors influencing demand and those influencing supply or at the macroeconomic level, where the AD-AS analysis rather replicates the microeconomic demand and supply analysis. The separation of

* University of Leeds, UK. I am grateful to participants in the Recent Developments in PostKeynesian Modelling conference, held at the University of Paris XIII, November 20-2I, 2009, and to two anonymous referees for comments on an earlier version.

Correspondence Address:

Malcolm Sawyer, Economics Division, Leeds University Business School, University of Leeds, Leeds LS2 9JT, UK, e-mail: m.c.sawyer@lubs.leeds.ac.uk.

Received II June 20IO, accepted I4 August 20IO

C) INTERVENTION 8 (2), 2OII, 28I-297 
the real and monetary sides of the economy is reflected in the classical dichotomy and the use of the term snatural to "try to separate the real forces from monetary forces « (Friedman I968: 9, following Wicksell). The ways in which the growth process has been modelled as converging on the snatural rate of growth is a further illustration. Ideas on the neutrality of money have rested on the separation of demand and supply factors and the absence of path dependency effects. In contrast, it is argued that interdependence of demand and supply, and associated with that the loss of any classical dichotomy which separates real and money sides of the economy, is (or should be) a central feature of heterodox macroeconomics.

In a world of fundamental uncertainty, where the future has yet to be discovered, the economy has to be viewed as path dependent. It is not just that 'history matters', but that it is impossible to perceive of a social world in which the paths of events do not set the stage for the subsequent events. The economy evolves as decisions are made and actions taken. There is not some pre-existing equilibrium route for the economy to follow around which the actual path of the economy may oscillate. This may all sound rather obvious, yet within the context of macroeconomic analysis the path dependency view runs counter to the prevailing manner in which economic analysis is conducted. The latter is firmly based on the idea that there is an equilibrium path around which the economy can travel which essentially preexists. Furthermore, when individuals are characterised as acting on the basis of rational expectations, part of the information set held by those individuals is knowledge of that equilibrium path. And, more significantly, there is an equilibrium path already sout there to which their decisions will essentially have to conform. In most economic analysis, where the economy starts and which path it follows through time does not affect the final equilibrium position in these models. This is related to a major weakness of this mainstream approach:

" [I]t is contradictory to adopt the rational expectations postulate that whatever change takes place in the future is already knowable and known in the present: that the economic change to be experienced is in a sense predetermined"

particularly in the context of models applying

"to modern economies - economies whose central functioning is the manufacture of change through their innovative activity and their adoption and mastery of the innovations made available« (Phelps 2007: xiv).

The paper now proceeds with a general discussion of the reasons for basing macroeconomics (and more generally economic analysis) on path dependency, the nature of path dependency and its relationship with the narrower concept of hysteresis. Sections 3, 4 and 5 review the ways in which path dependency necessarily arises in the context of the dual role of investment, the operations of the labour market and the evolution of technical change. In Section 6, we link the relationship between the short run and the slong run in the form of the cycle and the growth trend respectively, and the dual role of investment as a component of demand and addition to productive potential, with this leading to simple formulations of aspects of such path dependency to postulate the way to consider the growth process. 


\section{Path dependency and hysteresis}

The view that the modelling of the macroeconomy has to be based on path dependency comes from two interrelated propositions. The first is that the future course of the economy cannot be taken to be in any meaningful sense predetermined such that there is some (equilibrium) path already set around which the economy will necessarily travel. Hence, there is a rejection of the general notion of an equilibrium growth path which can be defined before the action starts and would in effect be known before decisions are made and around which the economy will actually operate. It would also follow from that observation that notions of rational expectations cannot operate - if the future is yet to be worked out, how can there be some (all) who already know that future in expectational terms.

The second is that decisions made today and the resulting actions and interactions must have an impact on what happens tomorrow and on the decisions which will be made tomorrow and the resulting actions. The decisions made are, of course, based on perceptions of the future: those perceptions of the future will in the event turn out to have been incorrect to a greater or lesser extent. It may indeed be difficult to ascertain whether the perceptions of the future were correct (or how incorrect they were) in that our perceptions of the future are generally imprecisely formulated and not expressed in numerical form. Further, individuals may form perceptions on a range of variables and situations, but this range is limited (in part due to issues of bounded rationality). The rational expectations approach is misleading in many ways, but two to note here would be the tendency to express expectations in numerical form and to consider that individuals form expectations over a wide range of economic variables.

Perceptions and expectations of individuals necessarily differ and there are no mechanisms by which, in general, the expectations of individuals are reconciled with one another (specifically there are few futures markets which could possiblly reconcile some expectations over prices). There is, though, a sense in which the outcomes that come from decisions based on those expectations involve some degree of reconciliation between those decisions in order to provide an outcome. There will always be disappointed expectations and perceptions arising from the differences between people. Further, there will be events, developments and outcomes in future time which could not be imagined in the present when decisions are made and actions taken. There is no possibility of being able to predict, accurately or otherwise that which cannot be imagined. In the words of Donald Rumsfeld

»there are known knowns - there are things that we know that we know. There are known unknowns. That is to say, there are things that we now know we don't know. But there are also unknown unknowns - there are things we do not know we don't know" (Statement at a Defense Department Briefing, February 12, 2002).

We can form expectations about what can be imagined but not about what cannot be imagined.

The rational expectations hypothesis involves the essential similarity of expectations between individuals with some differences arising from the information sets which individuals 
possess. But the underlying model of the economy on which rational expectations of individuals are generally based is in effect assumed to be known to all, and hence there is a similarity of expectations across individuals.

A particularly significant feature of the rational expectations approach is that the future path of the economy is taken to be already mapped out and essentially known to individuals (that is individuals expectations on the future deviate from what eventually arises only to the extent of non-systematic errors). There is assumed to be a situation of risk (that is individual decisions and actions are based on the probability distribution of future events). This can be contrasted with a situation of uncertainty in the Keynesian and Knightian sense which arises from the essential unknowability of the future, but there is risk in the sense of a probability distribution surrounding future events.

The term path dependency is used in preference to any notion of hysteresis (see Setterfield, 2009, for much more extensive discussion). In doing so we hope to emphasis that the economy is moving through time and the path (or paths) followed gradually open up and evolve: there is in effect no turning back even if some decisions can in some sense be reversed. The term hysteresis has been associated with the idea that there are alternative equilibrium positions. The nature of each of those potential equilibrium positions is not dependent on the route which is followed, though which of the equilibrium positions is attained does depend on the route followed as there has to be some mechanism by which one of the equilibrium positions comes to the fore over the others.

The term hysteresis can also be used to focus on issues of reversibility vs. irreversibility, whereas in a path dependent approach there is a passage through time and time itself is irreversible. The hysteresis approach in effect asks the following type of question. Suppose that a sposition of interest « which we will label $Y n$ (this could be something like the `natural rater of unemployment, or in the initial example drawn from physics the magnetic charge of an iron bar) which changes according to an equation such as $Y n_{t}=Y n_{t-1}+f\left(Z_{t-1}\right)$ and hence the position of $Y n_{t}$ can be solved back to give $Y n_{t}=Y n_{0}+\sum_{i=1}^{t} f\left(Z_{t-i}\right)$. The question can then be asked as to whether if $\sum Z_{t-i}=0$, does the expression $Y n_{t}=Y n_{0}$ hold? In the much-quoted hysteresis effects in magnetism, the equivalent of $\sum Z_{t-i}=0$ is imposed by the experimenter, and then $Y n_{t} \neq Y n_{0}$. In the context of much of macroeconomic analysis there may be some presumption that over some relevant time period $\sum Z_{t-i}=0$; a notable example of this which is rather pertinent for what we discuss below would be to take $Z$ as a measure of aggregate demand relative to some ^normak level, and hence over some `long run time period aggregate demand averages out at a ^normal level.

Irreversibility is a pervasive feature of (almost) all economic activity. This arises from (at least) two considerations. First, the pre-conditions do not exist which permit the reversal of decisions. If a person buys a tin of beans in the local supermarket, it is not usually possible for that person to sell the tin of beans back to the supermarket. Investment in machinery (and even more so in human capital) cannot be readily reversed by sale back to the producer or to other firms (and even smashing up the machinery does not mean a return to the initial state). Even if as far as the firm is concerned, an investment decision can be reversed in 
the sense that the investment good sold to another firm, the experience of operating the investment good, selling the resulting products etc., will have some impact on the firm's future behaviour. Second, time passes as decisions made at time $t$ cannot be reversed in time $t$, even if decisions made in time $t+1$ in some sense in the opposite direction to the decisions at time $t$. The supply of work is perhaps a good illustration of these two points: a person having sold their labour on day $T$ cannot buy back their labour in any meaningful sense and once day $T$ has passed the labour undertaken on that day cannot be brought back. On day $T+1$, the opposite decision to that made on day $T$ may be made but that cannot reverse the decision of day $T$.

These irreversibilities become significant when a decision taken today influences a decision tomorrow. When (as in the example given of the work decision) a different decision on a specified action in similar circumstance can be made at time $t+1$, then in a number of respects the decision made at time $t$ is reversed, and the decision at time $t$ may have no lasting effects. But when the decision at time $t$ and the resulting outcome (which may not fully accord with the intention) influences the decision at time $t+1$ (usually seen in terms of the decision at time $t$ leading to a similar decision at time $t+1$ ) then elements of path dependency arise. For example, when the decision (and actual experience) to work at time $t$ leads to a similar decision in time $t+1$, and when a decision not to, or inability to work at time $t$ would have lead to a different decision at time $t+1$, then path dependency comes in.

The path dependency approach is clearly located in historical time rather than in logical time. `Logical time is the type of ‘time as treated in models based on the principles of neoclassical economics. This is essentially the comparative statics approach in which an equilibrium is disturbed and the model automatically moves to a new, predetermined, equilibrium. How the system gets to the new equilibrium is of no central concern, in the sense that no attention is given to the process of getting from one equilibrium to the next following the disturbance. By contrast, 'historical time is the type of stime as treated in models, which treat the present as nothing exceptional. It is a moment in the passage from the past to the future, where the latter is of course unknowable. This is a dynamic process, in which equilibrium is of no concern since it is recognized that such a state does not exist in the real world. The actual process, therefore, of going from situation $A$ to situation $B$ is path dependent, and in the process determines the character of situation $B$ rather than the latter being predetermined.

The mechanisms by which there is path dependency and by which the path of demand opens up the future supply are various but in the context of macroeconomic analysis three are generally to the fore. The first one arises from the observation that current demand influences the level of investment (through capacity utilisation, profitability etc.) which thereby adds to the capital stock and future supply potential. This general idea can readily be extended to a range of investments including that in education and health provision.

The second is the way in which people are drawn into or pushed out of the effective labour supply through demand. Participation rates vary, ages of entry into and exit from the labour force change and there is regional and international migration. Clearly not all of such changes can be ascribed to pressures of demand as demographics, changes in social 
attitudes etc. are involved. But the evolution of the labour force cannot be understood without reference to demand.

The third arises in general terms through technical change. In the specific contexts of macroeconomic analysis, this can be portrayed in terms of the factors influencing the level of research and development expenditure, the manner in which new ideas are incorporated through investment and so on. In the discussion below this is represented by the operation of a Verdoorn law type effect and learning by doing ( and a variety of other forms of learning, e.g. slearning by exporting). The rate of productivity change is then linked with the level of activity in the economy, which itself is determined by the level of demand. This clearly only covers part of the evolution of the economy but one which has been to the fore in macroeconomic analysis (especially of the Kaldorian variety).

\section{Path dependency and the labour market}

The representation of the labour market used in most macroeconomic analysis is straightforward. There is a downward sloping demand for labour curve (in terms of the real wage) and an upward sloping supply of labour curve (also in terms of the real wage), and equilibrium in the labour market is given where demand and supply are in equality. The state of being employed or being non-employed (which may be labelled unemployed) comes from the voluntary decisions which individuals make in the face of real wages. The present level of real wages (actual and expected) is then sufficient to predict the levels of employment and unemployment. There is then nothing from the past that is seen to influence today's demand and supply decisions, and hence today's real wage and employment levels. It is an important feature of this approach that employment and unemployment arise from voluntary decisions.

Once it is acknowledged that the level of aggregate demand is significant in the setting of the levels of output and employment, then unemployment has to be viewed as involuntary for many of those who suffer from it and has to be seen as a macroeconomic rather than a microeconomic phenomenon (see Sawyer/Spencer 2008). It is then obvious that unemployment and employment are demand determined. But this does not in itself create path dependency in so far as it is the current level of demand which determines the current level of unemployment. Path dependency can then arise from the effects of the experience of unemployment and employment on people's decisions on seeking work. It also depends on the ability of firms to provide employment, which depends on the productive capacity of the economy, including the capital stock built up from previous investment decisions. Once it is acknowledged that experience matters, then path dependency arises. This could to some degree be introduced into the new classical macroeconomics approach if it could be acknowledged that non-employment, arising from misperception of wages but voluntarily chosen nevertheless, changed a person's attitude to work and leisure. But the argument becomes more powerful when unemployment comes through force of circumstance, e.g. from a downturn in aggregate demand. Unemployment may take the form of being registered as 
unemployed and seeking work but may take a number of other forms such as withdrawal from the work force, early retirement and incapacity. The experience of unemployment, particularly when extended for the individual, may lead to de-skilling, loss of work ethic, and ill health. Some have highlighted the sscarring effects of unemployment, which impact on the future employment and future earnings of workers (see, for example, Arulampalam et al. 200I).

The size of the labour supply will be influenced by legal and social norms and would change over time as those norms themselves change. In terms of demand effects, the level of aggregate demand may not have an immediate effect on the labour supply, though a persistently high (or indeed low) level of aggregate demand could be expected to impact on legal and social norms, and thereby on the labour supply. Hence, social pressures may intensity for a reduction in what are regarded as normal working hours where very high levels of unemployment exist and persist over time. But the level of aggregate demand would impact on the labour force with high levels of aggregate demand bringing people into the labour force who had previously been in the sdiscouraged worker category, and low levels of demand and subsequently unemployment leading to people dropping out of the labour force or becoming effectively de-skilled. High levels of demand for labour may have a range of effects ranging from spulling people into the work force from the home through to encouraging migration from other countries (for further discussion see Sawyer and Spencer [20IO]).

Wage setting provides a further route through which path dependency is likely to arise. When ideas of norms and fairness impact on the setting of wages, and the evolution of those norms and notions of what is fair dependent on the path of the economy, then wages are to be viewed as path dependent (for an example of fairness as a source of path dependency see Skott [2005]).

Unemployment has sscarring effects on individuals and there is demoralisation felt by workers in the face of heightened job insecurity, which tend to reduce productivity. In terms of path dependency and hysteresis with regard to labour supply this would require some form of change in tastes and preferences in response to actual experience which would undermine the assumption of exogenous tastes and preferences made in the conventional neoclassical models of labour supply, and also serves to undermine the separation between the supply of labour and the demand for labour assumed in standard macroeconomic analysis.

An increase in unemployment can set up many forces, economic, social and political, some of which may tend to push unemployment up further and others tend to reduce unemployment. There may be some reversion towards the historical average rate of unemployment, but that does not mean that there is no path dependency. Some reversion does not necessarily mean complete reversion, and any long-term average is just that - the average - which need not have any equilibrium connotations.

The unemployment rate is, of course, a ratio between (measured) unemployment and the labour force. Even if the unemployment rate were to revert back to some historical average, the meaning and significance of that rate may well be different. Labour force participation can respond to the path of aggregate demand. In that case, the size of the economy (as measured by labour force) changes over time in a path dependent way. 
In the context of the labour market, path dependency comes from many sources. The experience of unemployment and employment on the skills, work commitment and attitudes of workers; entry into the labour force and migration to another country in response to employment opportunities are not readily reversed. Some of these effects may be reversed but others are unlikely to be. For there not to be path dependence, there would have to be factors which promote reversibility, with the scale of those factors exactly offsetting the initial changes. For example, if a high level of demand pulled people out of the rural economy into the industrial sector, then for an absence of path dependency there would have to be low levels of demand sufficient to push those people back from the industrial sector into the rural economy.

\section{Moulding demand and supply together: The role of investment}

Post-Keynesians and Kaleckians would see that a key feature of investment is that the results from the investment decisions have long-lasting effects and (more significantly here) cannot be readily reversed, and influence the future productive potential. Further, investment decisions today influence tomorrow's capital stock and productive capacity, which forms the background to tomorrow's decisions on investment. In the neoclassical investment function (Jorgenson 1963) investment decisions depend on relative prices and can be readily reversed (there is nothing that rules out negative investment at the firm level and then by aggregation at the aggregate level). In post-Keynesian and Kaleckian approaches, investment decisions are undertaken in an uncertain environment, influenced by past experience and perceptions of the future, and in particular by the macroeconomic environment in terms of capacity utilisation, growth and profitability. The path followed by aggregate demand impacts on the macroeconomic environment which has further effects on investment and the future capital stock.

In the context of macroeconomic analysis, there are many features of investment which are at the same time well known in heterodox macroeconomics; unsurprisingly, though, barely mentioned in many mainstream circles. Still, these features are highly relevant for a path dependency approach to macroeconomic analysis. The first is that the essential property of investment (whether in the form of fixed capital equipment or in the form of education) is that it is intended to bring future rewards and benefits. Investment, which occurs in the present, is intended to have future effects by the definition of what constitutes investment. This leads to the observation that decisions on investment are strongly influenced by perceptions of the future by the decision maker. But the future is uncertain and inherently unknowable. It is then not a matter of the future setting what is done in the present, but rather postulates about the future influencing what is done in the present, and those actions in the present setting the scene for the future.

The second remark is that, in macroeconomic terms, the level of investment is a significant component of aggregate demand. As such the level of investment, which takes place, has a significant impact on the resulting level of economic activity. We may articulate 
this argument in a simple representation in the equation $s_{p} P=I$, where $s_{p}$ is the propensity to save out of profits $(P)$, and $I$ is investment. The conclusion to draw is that profits depend on investment, but the investment which occurs depends on the perceptions of what profits are expected to be.

Third, "many if not most innovations need to be embodied in new kinds of durable equipment before they can be made effective« (Solow 1960: 9I). There is then an intimate link between technical change and investment. Decisions made on investment impact on technical change, if and when innovations are made and if and when new ideas are incorporated into practice.

Fourth, investment takes many forms, and with specific reference to fixed capital formation, it is not just the quantity of investment that is relevant but its quality and structure. The manner in which different sectors of the economy (e.g. manufacturing, agriculture) develop depends on the investment which is taking place in the sector. Further, the nature of the capital equipment and its rate of change is not constant over time. This undermines the use of a single variable for capital stock in a model of the economy. Growth is not a matter of more of the same. Even when it is more of the same, the amount of the samer (in terms of the capital stock) depends on decisions on investment.

When the growth path is already set, as in the neoclassical growth model, then the growth of the capital stock, which is of course determined by net investment, has to move towards that growth rate. The Keynesian approach to investment involves sthe state of expectations and in that sense is forward looking. But perceptions of the future are much moulded by present and past experience. There are elements of adaptive expectations with regard to key variables such as profitability and growth prospects.

In this paper, attention is drawn to some aspects of investment and capital formation for the supply side of the economy. Investment in many respects links together the demand side and the supply side of the economy in the sense that investment is a major component of aggregate demand and investment is capital accumulation influencing the development of the supply side of the economy. Decisions made on investment depend on a wide range of factors including the state of present and prospective demand, profitability and ranimal spirits`, and technological factors. The path followed by the economy as reflected in the variables (and others) just mentioned would then influence the investment which takes place. In turn, the investment which occurs helps to set down the next steps for the economy in terms of the evolution of the supply potential of the economy.

\section{Moulding demand and supply together: Technical change}

Technical change and the development and implementation of new ideas, introduction of new products and processes are probably the clearest cases of the need to incorporate path dependency. The idea of slock-in « effects provides a clear example of the notion that when a new idea is introduced it has subsequent effects on the path of the economy. The whole process of research and discovery involves that the development of new ideas, processes etc. 
has to build on the previous ones. The development of new ideas cannot be other than path dependent. Technical changes and the development of new ideas and new solutions cannot be foreseen - in effect if a new idea could have been foreseen it would not have been a new idea! There is a close linkage between technical change and fundamental uncertainty. It is because research and technical change involves something new that past experience cannot be used to generate some probability distribution of future events. Rolling the dice many millions of times in the past generates confidence that the probability distribution for future rolls of the dice are such that there is a one-in-six probability for each number on the dice to be rolled. The experience of the discovery and development of electricity does not provide any probability distribution for some future major invention. Technical change involves uncertainty rather than risk.

In the context of technical change, the conditions of demand (whether at the level of the economy or of a particular industry) are relevant for the pace and nature of technical change in a number of ways. One way, which is widely drawn upon in the macroeconomics literature, relates to learning by doing . The term / learning by doing، captures two key features - that there is learning and that there is sdoing. For the individual, learning involves the acquisition of new (as far as that individual is concerned) knowledge, and there is a sense in which learning is not readily reversible; indeed, there can be a process of unlearning in the sense of lagging behind new developments. The concept of learning by doing though goes further in the sense that what is learnt is often new for society as a whole not merely for the individual. The extent of doing is, of course, related to the level of demand. Verdoorn's Law (using the common terminology though having the status of a law seems rather strong) is generally expressed in terms of rate of productivity change as a function of the rate of growth of output, with the assumption that growth of output is demand driven (and that it is positive). In many versions, Verdoorn's Law may be limited to certain sectors of the economy (notably manufacturing). In our analysis in the next section we use Verdoorn's Law as an expression of the idea that the pace of change is linked with demand. This is intended to be illustrative rather than definitive, and a fuller analysis would require more exploration of that idea.

There are clearly other ways in which the general conditions in the economy influence decisions made on technical change and research and development, and hence ways in which the path of demand impacts. Research and development does after all have to be financed and when undertaken by private firms have to be perceived as profitable (though given the uncertain nature of research and its outcomes, the formation of those perceptions also become highly relevant).

\section{Moulding demand and supply together in the growth context}

In the context of macroeconomic analysis, the interplay of aggregate demand and supply potential not only undermines the classical dichotomy but more significantly here provides important elements of path dependency. There are movements in aggregate demand which are 
a significant feature of the path of the economy, with movements arising from a wide range of factors including ranimal spirits, government policy and technological opportunities. The question is then whether there is path dependency in the sense that demand impacts on the evolution of supply potential, and hence that the evolution of supply potential can only be understood with reference to the path of aggregate demand (and other factors outside the scope of this paper).

In the approach sketched here it is proposed to model investment and saving decisions in each period, and to build up possible growth scenarios from that. A shortcoming in the present formulation is that insufficient attention is given to accelerator factors which would generate cycle-like movements, and this is something to be added (and in a similar vein movements in wages and prices, and specifically shifts in real wages and profits could also be added). But policy measures (fiscal policy) are explicitly included. Further, the effects of demand on technical change and labour force participation are introduced, albeit in a very simplistic manner.

In a path dependent world, models of economic growth are required in which there is no equilibrium growth path sout there (as in the neoclassical case); and each step along the growth path depends on the previous steps which have been taken. There is also here the illustration of ways in which the path of demand influences the evolution of supply, and also how demand factors have a long-term impact on the growth of the economy.

In a path dependent world where the step taken in time $t$ forms the basis for the steps, which can be taken in time $t+1$, the path followed by the economy has to be built up step by step. Further, at each stage, decisions have to be made, choices exercised etc., in some human agency, so that there is no predestination involved. In this section we do not attempt to present a complex model along these lines, but rather to illustrate the basic ideas.

The way we proceed is by a form of construction of possible scenarios, with certain steps being specified and some ways in which the economy tends to change processes postulated to investigate the possible growth path. The emphasis is on the role of demand, and the ways in which supply may change in response to demand. The saving function starts from the proposition that $s$ is the propensity to save out of profits, and for simplicity it is assumed that there are no savings out of wages. The saving function is then expressed as:

$$
\frac{S}{K}=\frac{s m u}{v}+\mu_{1},
$$

where $S$ is saving, $K$ a measure of the capital stock, $s$ the propensity to save out of profits, $m$ the share of profits in national income, $u$ a measure of capacity utilisation and $v$ the capital(capacity) output ratio and $\mu_{1}$ a term reflecting other influences. The investment function is assumed to take a form such as:

$$
\frac{I}{K}=a+b\left(u-u^{*}\right)+c m+e \Delta u+\mu_{2},
$$

where $u^{*}$ is some measure of desired capacity utilisation (as far as enterprises are concerned in terms of costs and profits), $\Delta u$ change in capacity utilisation, $\mu_{2}$ a term reflecting other influences. This equation reflects the influence of both capacity and profitability on 
investment decisions (noting that the rate of profit is equal to $m u / v$ ). The coefficient $a$ can be thought of as reflecting a range of influences on investment including sanimal spirits and the technological developments. This formulation does not reflect any notion that firms know the future in the sense of holding rational expectations on the future which are the basis of their decisions. It reflects the effects of current experience on the economy (through capacity utilisation and profitability), with that current experience influencing perceptions of the future, and that it is strongly influenced by demand. The inclusion of profitability reflects a number of factors including the availability of internal funds for investment as well as the returns on capital. It is also taken as a proxy for firms' views on future prospects. There are waves of optimism and pessimism, which can change the balance; in Keynes's terminology ranimal spirits vary over time in ways which are not reflected in the macroeconomic variables. The analysis of any specific period based on this type of approach would need to take into account factors such as technological developments and their implications for investment opportunities and the state of animal spirits and the general assessment of future prospects.

The term $d$ is used to denote the net injections (into the circular flow of income) from outside the private sector (relative to the capital stock), and as such this includes the budget deficit, and hence $d$ can be thought of as the budget deficit relative to the capital stock (in an open economy context $d$ would also involve the net export position).

Within a specified time period, the equality between leakages and injections, and hence assuming that capacity utilisation adjusts, yields:

$$
\frac{s m u}{v}+\mu_{1}=a+d+b\left(u-u^{*}\right)+c m+e \Delta u+\mu_{2},
$$

which can be solved to yield the capacity utilisation at time $t u(t)$ and one-period growth of capital stock from time $t-1$ to time $1 g_{K}(t)$ as:

$$
\begin{aligned}
& u(t)=\frac{\left(a(t)+d(t)-b u^{*}(t)+c m(t)+e \Delta u(t)+\mu_{2}(t)-\mu_{1}(t)\right) v}{s m(t)-b v}, \\
& g_{K}(t)=\frac{s m(t)\left(a(t)+d(t)-b u *(t)+c m(t)+e \Delta u(t)+\mu_{2}(t)-\mu_{1}(t)\right) v}{s m(t)-b v}+\mu_{1}(t) .
\end{aligned}
$$

It is assumed that the Keynesian stability condition holds so that $s m-b v>0$. The growth rate here is the one-period change in the capital stock, and would only imply something about the trend rate of growth if the key parameters remained unchanged. But the approach here has been framed such that many of the key parameters would be expected to change over time. Equations (4) and (5) indicate that capacity utilisation and the one-period growth rate of capital depend positively on the fiscal stance $(d)$. A given (primary) budget deficit to income ratio will lead to convergence on a debt income ratio provided that the growth rate is greater than the rate of interest on government debt, and hence in this model a higher budget deficit is more likely to be sustainable than a smaller one, since the growth rate is higher and hence the stated condition more likely to be satisfied. However from a demand stimulus perspective it is the total budget deficit which is relevant and to which the term $d$ 
above relates. The debt income ratio would then converge on $d / g$ when the deficit of $d$ is maintained and $g$ is the growth rate over the appropriate time horizon.

The capital stock is then perceived to evolve according to equation (5), and hence the capital stock at time $T$ is given by:

$$
K(T)=K(0) \prod_{1}^{T}\left(1+g_{K}(t)\right) .
$$

This suggests that the scale of the economy, as measured here by the capital stock, is path dependent and influenced by the path of aggregate demand, provided that the growth rate in each period can be taken as demand determined which it is in the above model. The question can then become whether there are forces which ensure that the growth of the capital stock conforms to some snaturak rate of growth, which is taken up below.

The level of output is taken to be related to the capital stock in the following manner:

$$
Y(t)=\alpha u(t) K(t)
$$

where $\alpha$ is the output to full capacity capital ratio which for simplicity is assumed to be constant over time. The labour force in number of person (or person hours) is denoted by $N(t)$ (which may be thought of as the labour supply), and through acquisition of education, training etc. summarised by the measure $E$, the reffectiver labour supply $F(t)$ is equal to $E(t) N(t)$. The level of employment is demand determined and depends on the level of output, and is taken to be $L(t)=Y(t) / l(t)$ where 1 is labour requirement per unit of output which will be taken to decline over time. The employment rate of $L(t) / F(t)$ can be expanded into $Y(t) / l(t)$ $E(t) N(t)$. The growth of employment in each period will then be where the terms relate to the growth rates of capacity utilisation, capital stock and of labour requirement per unit of output respectively, and hence the employment level at time $T$ is given by:

$$
L(T)=L(0) \prod_{1}^{T}\left(1+g_{u}(t)+g_{K}(t)-g_{l}(t)\right) .
$$

The trend rate of growth of the capital stock can be calculated from equation (6) as the growth rate $g^{p}$ which gives $\left(1+g^{p}\right) t=K(t) / K(0)$. In a similar vein the trend rate of growth of output would be derived from a comparison between $Y(t)$ and $Y(0)$. It is then self-evident that the capital stock is path dependent, where from equation (5) fiscal policy $(d)$ and animal spirits (a) along with the terms such as $\mu_{1}$ and $\mu_{2}$ are significant parts of the path which is followed.

This framework so far merely indicates that the scale of the economy would be path dependent, where the nature of the path followed in this framework is one influenced by the level of aggregate demand. But the next stage would be to integrate ways in which the variables which have been identified in the above equations may interact and evolve over time. For example, the fiscal stance $d$ has been postulated as influencing $u$ and $g_{K}$ and in turn the way in which $d$ could evolve over time could be investigated with subsequent effects on the scale of the economy. In a similar vein, the other variables identified above including animal spirits $(a)$, profit margins $(m)$ and desired capacity utilisation $\left(u^{*}\right)$ can also be seen to evolve over time. There are numerous suggestions which can be worked on in this contextthat the desired capacity utilisation responds to actual experience of capacity utilisation and 
that the profit margins change in the face of capacity utilisation differing from the desired level are two examples.

The outline above is based on the growth rate being set by demand-side considerations - though the growth rate would change over time in response to the evolution of the key parameters. There is also a growth rate of supply potential, and the question of the interactions between growth based on demand and growth of supply potential arises.

The growth of the effective labour supply $g_{S}$ is given by $g_{S}=g_{E}+g_{N}$ where $g_{E}, g_{N}$ are growth rate of effectiveness of labour and of the labour force respectively.

The growth of the demand for labour (from above with capacity utilisation taken as constant) is $g_{d}=g_{K}-g_{l}$. As this stands there is no particular reason to think that $g_{d}$ and $g_{S}$ will be equal to one another, and hence there would be a tendency for the employment rate to have a distinct trend.

In order to explore a little the demand-side and supply-side rates of growth, the ways in which the terms $g_{l}, g_{e}$ and $g_{n}$ may be influenced by the level of and rate of increase of demand are considered. The growth rates used here are treated as the average rates over a significant period of time.

There are numerous arguments associated with `learning by doing`, the application of Verdoorn's law and the stimulus of demand on research and development, which could be seen to lead into the effects of the level and growth of demand on technical change and labour productivity. This is summarised here in terms of the effects of growth of capital stock (demand driven) and capacity utilisation on growth of labour requirements as:

$$
g_{l}=a_{1}-a_{2} g_{K}-a_{3} u
$$

with $a_{2}$ and $a_{3}$ being positive and reflecting that $g_{l}$ is the labour requirement per unit of output.

Investment in education and training is presumed to lead to a more effective work force. High levels of demand help to 'pull people into the labour force, whereas low levels of demand 'push ' people out of the labour force. It is then postulated that the growth of the effective labour supply is also dependent on growth of capital stock and capacity utilisation, as:

$$
g_{s}=b_{1}+b_{2} g_{K}+b_{3} u \text {. }
$$

A range of policy measures which influence research and development, levels of education and training, and laws governing immigration could be seen as reflected in the term $b_{1}$. The equality between $g_{K}$ and $g_{l}+g_{S}$ would give

$$
g_{K}=\frac{a_{1}+b_{1}+\left(b_{3}-a_{3}\right) u}{\left(1-b_{2}+a_{2}\right)} .
$$

The rate of growth which satisfies equation (11) clearly reflects supply aspects (through $a_{1}$ and $b_{1}$ ) and demand aspects (through $u$ directly and it could be said through the other parameters). It could be seen as a demand-augmented `natural rate of growth.

The growth of employment is $g_{L}=g_{l}+g_{K}$, and the growth of the effective labour supply is $g_{S}$. It is the difference between $g_{L}$ and $g_{S}$ which is significant for the change in the employment rate, and equality between them required for a constant rate. It is convenient 
in terms of Figure I to work with $g_{K}$ and $\left(g_{l}+g_{S}\right)$, rather than $g_{l}$ and $g_{S}$. In Figure I the relationship from equation (II) is placed alongside the saving equation $(S / K)$ and the investment equations $\left(I / K=g_{K}\right)$. The demand-side growth rate (coming from interaction of saving and investment equations) and the demand-augmented supply-side growth rate will in general differ. The rate of capacity utilisation $u$ given by the swarranted rate of growth would be $u_{a}$ with corresponding growth rate of $g_{a}$, whereas the 'warranted rate of growth and the snatural rate of growth ' would be equal at a capacity utilisation rate of $u_{b}$, and a growth rate of $g_{b}$. Fiscal policy would enable the gap between $S / K$ and $I / K$ at $u_{b}$ to be filled and hence the economy could operate at $u_{b}$.

\section{Figure I: Configuration of growth from demand perspective and of supply potential}

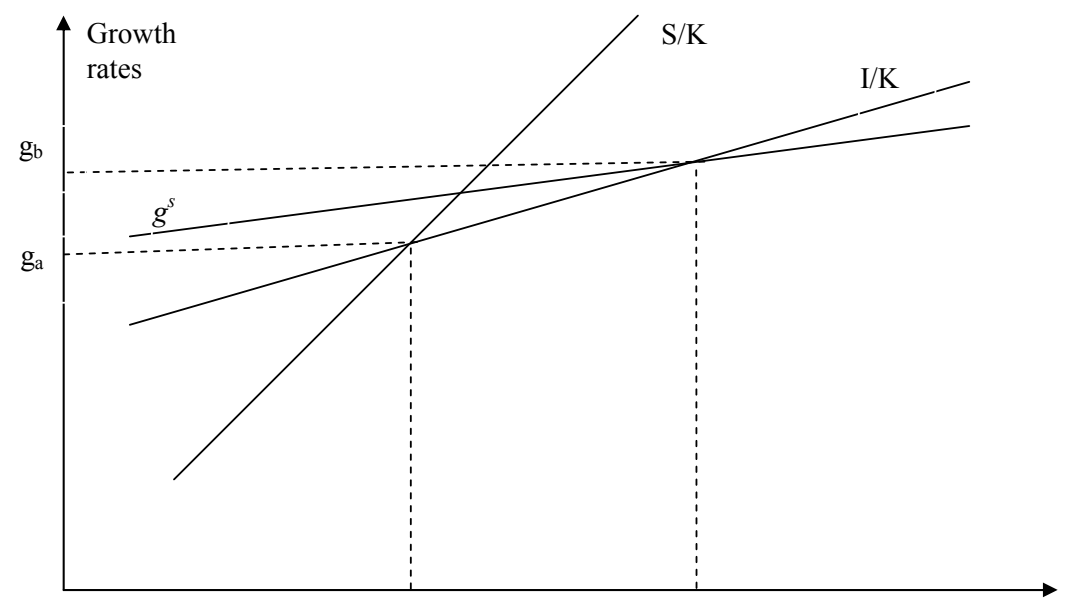

The key issue is whether and how these differences between the demand and supply side views could be reconciled. In effect, are there forces at work which would lead to shifts in one or more of the curves such that all three intersect at a single point and in effect $u_{a}$ and $u_{b}$ converge as then would $g_{a}$ and $g_{b}$. For a demand perspective the economy would be expected to operate around $u_{a}$, and there $g_{s}$ exceeds $g_{K}$, and the growth of supply exceeds the growth of demand. This could be viewed in terms of whether the difference between the growth of employment (demand determined) and the growth of labour supply has any impact on either the demand-side or the supply-side growth rate. The answer to that question would go some way towards forming a view as to the extent to which growth can be deemed to be demand or supply determined.

There are no doubt numerous mechanisms which could be invoked, and here we illustrate two. Dutt (2006) proposes (his equation 5) that the constant term in the investment equation changes over time in a manner which depends negatively on the difference between the growth of employment and the growth of labour supply. In terms of the above figure 
that would translate into the investment function shifting in response to the difference between $I / K$ and $g_{n}$. Specifically, at capacity utilisation such as $u_{a}$, the $I / K$ curve would shift upwards in response to $\left(I / K-g_{n}\right)$, and continue to do so until a configuration such as that given in Figure 2 were reached.

Figure 2: Reconciled demand-determined and supply-determined growth

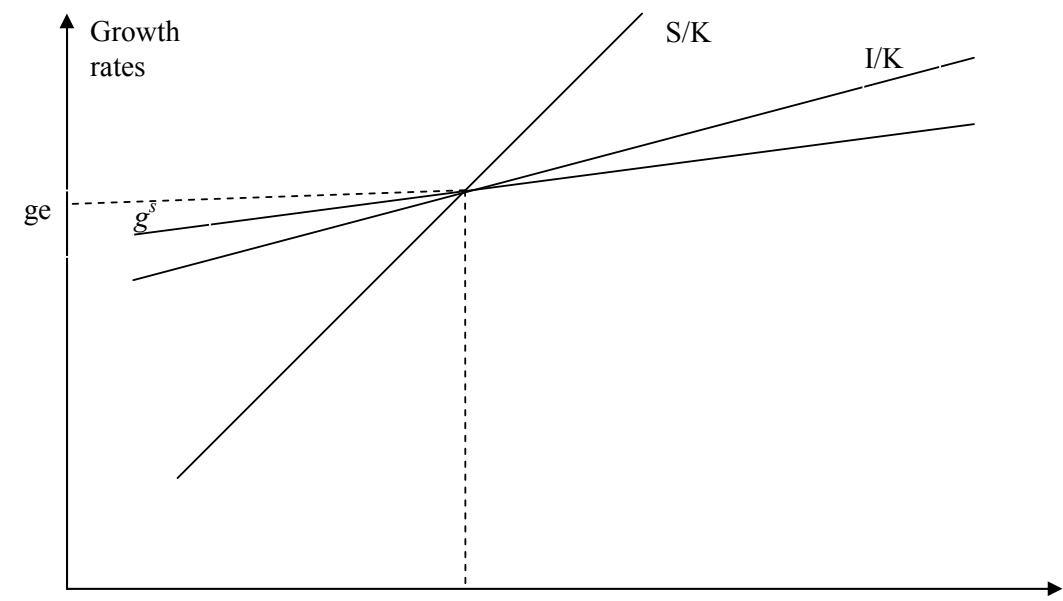

Dutt (2006) also postulates (his equation 8) that the rate of growth of labour productivity depends positively on growth of employment minus growth of labour supply. This would be reflected in Figure I by a downward shift in the $g_{n}$ curve (starting from a point such as $u_{a}$ ). This again would continue until a configuration such as in Figure 2 were reached.

It should also be noted that fiscal policy which absorbs the difference between planned saving and planned investment could also be utilised in this context. A budget deficit equivalent to the distance between the $S / K$ and $I / K$ curve at capacity utilisation $u_{b}$ would enable the economy to operate at $u_{b}$ and to secure growth of $g_{b}$.

Here we have sought to provide a framework within which to sketch the following arguments. First, the scale of the economy at each point in time can readily be seen to be path dependent, and in the specific example, dependent on the path of demand. Second, the manner in which the economy would evolve over time would also crucially depend on how the key parameters of the economy evolve, and in the framework here these have been seen as profit margins, desired capacity utilisation, sanimal spirits and fiscal policy. Third, the relevance of demand for the evolution of supply has been modelled in a rather simple way from which a demand-augmented growth of supply equation can be derived. The growth of demand and the growth of supply potential could be seen to evolve at different rates but interactions between them can be foreseen which could bring them towards each other. 


\section{Conclusions}

This paper has sought to argue that macroeconomic analysis should be firmly based on ideas of path dependency. It has sought to illustrate the manner in which issues of path dependency arise in the context of investment, technical change and labour force. Specifically for macroeconomic analysis we argue for the essential interdependence of demand and supply, and that the course of demand influences the path of supply. We have sought to illustrate these points with regard to a simple framework for growth analysis.

\section{References}

Arulampalan, W, Gregg, P., Gregory, M. (200I): Unemployment scarring, in: Economic Journal, $\operatorname{III}(3), \mathrm{F}_{577-584 .}$

Friedman, M. (1968): The role of monetary policy, in: American Economic Review, 58(I), I-I7.

Frydman, R., Goldberg, M.D. (2007): Imperfect Knowledge Economics: Exchange Rates and Risk, Princeton: Princeton University Press.

Jorgenson, D. (1963): Capital theory and investment behaviour, in: American Economic Review, $53(2), 247-259$.

Kalecki, M. (197I): Selected Essays on the Dynamics of the Capitalist Economy, I933-1970, Cambridge: Cambridge University Press.

Phelps, E.S. (2007): Introduction, in: Frydman, R., Goldberg, M.D., Imperfect Knowledge Economics: Exchange Rates and Risk, Princeton: Princeton University Press, xiii-xx.

Sawyer, M. (1982): Macroeconomics in Question, Brighton: Harvester-Wheatsheaf.

Sawyer, M. (200I): The NAIRU, aggregate demand and investment, in: Metroeconomica, 53(I), 66-94.

Sawyer, M., Spencer, D.A. (2008): On the definition of involuntary unemployment, in: Journal of Socio-Economics, 37, 718-735.

Sawyer, M., Spencer, D.A. (2010): Labour supply, employment and unemployment in macroeconomics: A critical appraisal, in: Review of Political Economy, 22(2), 263-279.

Setterfield, M. (2009): Path dependency, hysteresis and macrodynamics, in: Arestis, P., Sawyer, M. (eds.), Path Dependency and Macroeconomics, Basingstoke: Palgrave Macmillan, $37-79$.

Skott, P. (2005): Fairness as a source of hysteresis in employment and relative wages, in: Journal of Economic Behavior and Organization, 57, 305-33I.

Solow, R.M. (1960): Investment and technical progress, in: Arrow, K., Karlin, S., Suppes, P. (eds.), Mathematical Methods in the Social Sciences, Stanford: Stanford University Press, 89-IO4. 
